\title{
Relationship between pairing frequencies and genome affinity estimations in Aegilops ovata $\times$ Triticum aestivum hybrid plants
}

\author{
BEGOÑA FERNANDEZ-CALVIN \& JUAN ORELLANA \\ Departamento de Genética, ETSI Agrónomos, Universidad Politécnica de Madrid, 28040 Madrid, Spain
}

\begin{abstract}
Meiotic associations at metaphase I have been analysed in Aegilops ovata $\times$ Triticum aestivum hybrid plants (genome constitution ABDUM) with low and high homoeologous pairing by using C-banding. Five different types of meiotic associations involving Aegilops and wheat genomes were identified. Pairing affinities between Aegilops and wheat genomes have been analysed from meiotic associations at metaphase $\mathrm{I}$ in low and high homoeologous pairing hybrid plants as well as from different meiotic configurations (bivalents and multivalents) in those hybrids with a high pairing mutant $(p h l b)$. Those kinds of distinguishable associations revealed the same relative order: $\mathrm{AD}-\mathrm{UM}>\mathrm{A}-\mathrm{D}>\mathrm{U}-\mathrm{M}>\mathrm{AD}-\mathrm{B}>\mathrm{UM}-\mathrm{B}$ in both low and high homoeologous pairing hybrids. The mean number of associations per total associations (relative contribution) for the different distinguishable types of pairing was well maintained among hybrids with different levels of pairing (low and high) as well as in different meiotic configurations (bivalents and multivalents) in the high pairing plants. These results seem to indicate that the affinities expressed between the genomes that are in competition for pairing are independent of the meiotic configurations considered and on the level of pairing analysed.
\end{abstract}

Keywords: Aegilops ovata, C-banding, genome analysis, homologous pairing, wheat hybrids.

\section{Introduction}

In the tribe Triticineae, genomic analysis (based on chromosome pairing in interspecific hybrids) has been extensively employed (Lilienfeld \& Kihara, 1951; Kimber, 1984). The studies of evolutionary relationships have two inter-related concerns: theoretical and practical. The species related to wheat could be useful in wheat improvement because they are resistant to wheat diseases, such as stem rust and mildew (Pasquini, 1980). The analysis of cytogenetic relations could provide information about the success of transferring them into cultivated wheat from wild species.

Meiotic behaviour in wheat is regulated by genes that affect chromosome pairing (see Sears, 1976). The gene $P h$, located on the long arm of chromosome 5B, has the most important effect and its inactivation induces homoeologous pairing in hybrid combinations. The manipulation of such a genetic system allows homoeologous pairing between wheat and Aegilops chromosomes and therefore is valuable in transferring useful characteristics into crop species (Thomas, 1981; Riley et al., 1981).

Ae. ovata $\times T$. aestivum hybrid plants with low and high pairing have been analysed on several occasions to determine the meiotic behaviour and genetic regulation of chromosome pairing (Abu Bakar \& Kimber, 1982; McGuire \& Dvorák, 1982; Claesson et al., $1990)$ and the possibility of transferring some useful characteristics (Lacadena \& Azpiazu, 1969; Farooq et al., 1990); but in those studies meiotic pairing was considered as a whole because no cytological marker was available to determine genome-specific associations in the hybrids.

The use of C-banding methods allows more detailed studies to be made of chromosome pairing at metaphase I in interspecific combinations in order to determine patterns of pairing between different genomes that are in competition, and can provide an important advance over conventional pairing analysis.

The purpose of this work was to analyse the meiotic associations between different genomes at metaphase I 
in Aegilops ovata $\times$ Triticum aestivum interspecific hybrid combinations with low and high homoeologous pairing by using a $\mathrm{C}$-banding method.

\section{Materials and methods}

Pentaploid hybrid plants (genome constitution ABDUM) were obtained from crosses between allotetraploid Aegilops ovata (Aeov) (genome constitution UUMM) as female and hexaploid wheat Triticum aestivum cv. Chinese Spring (CS) and its high pairing mutant (ph1b) (Sears, 1977) (genome constitution AABBDD) as males. In order to obtain meiotic cells, anthers of Aegilops-wheat hybrids were fixed in acetic: ethanol $1: 3$ and stored for $1-4$ months at $3-4^{\circ} \mathrm{C}$. The fixed material was squashed and stained following the Giemsa C-banding technique described previously (Giráldez et al., 1979).

\section{Results and discussion}

\section{General aspects of pairing in the pentaploid hybrids}

The pairing was extremely low $(0.88$ associations per cell) in the hybrids of Ae. ovata with Chinese Spring (AeovCS), only open bivalents were observed and multivalents were not found (see Fig. 1 and Table 1). The level of pairing increased considerably in those hybrids in which the $P h$ locus was inactive (Aeovph1b) (13.43 associations per cell) and multivalents were frequently observed (see Fig. 2a and Table 1). If all

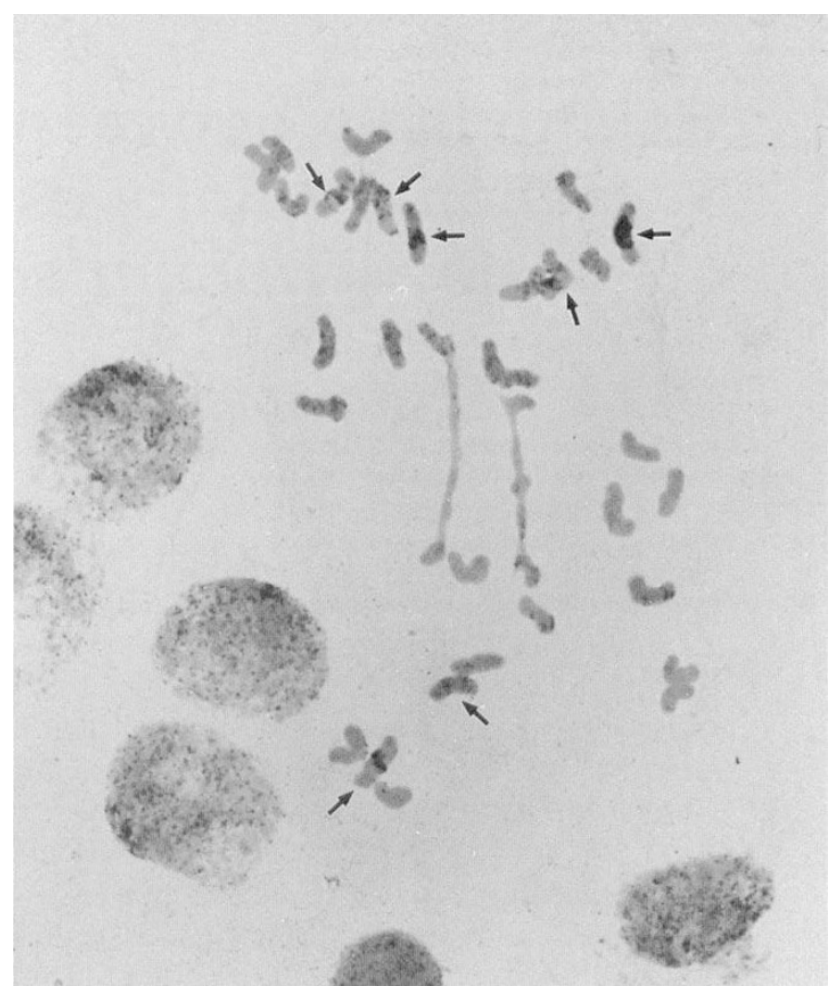

Fig. 1 Metaphase I of AeovCs hybrid plant. Arrows indicate chromosomes of $\mathrm{B}$ genome.

chromosomes for a given homoeologous group were paired, the largest meiotic configuration to be expected should be a pentavalent, however hexavalents were found in high homoeologous pairing hybrid plants.

Table 1 The number of different meiotic configurations observed for the five distinguishable types of pairing in the low and high homoeologous pairing hybrid crosses

\begin{tabular}{|c|c|c|c|c|c|c|c|c|c|c|c|c|c|c|c|c|c|c|}
\hline \multirow[b]{4}{*}{ Plants } & \multicolumn{18}{|c|}{ Meiotic configurations } \\
\hline & \multicolumn{10}{|c|}{ Bivalents } & & & & & & & & \\
\hline & \multicolumn{2}{|c|}{ AD-UM } & \multicolumn{2}{|c|}{$\mathrm{AD}-\mathrm{B}$} & \multicolumn{2}{|c|}{ UM-B } & \multicolumn{2}{|c|}{$A-D$} & \multicolumn{2}{|c|}{$\mathrm{U}-\mathrm{M}$} & \multicolumn{3}{|c|}{ Univalents } & \multicolumn{4}{|c|}{ Multivalents } & \multirow{2}{*}{$\begin{array}{l}\text { Number } \\
\text { of cells }\end{array}$} \\
\hline & $\mathrm{O}$ & $\mathbf{R}$ & $\mathrm{O}$ & $\mathrm{R}$ & $\mathrm{O}$ & $\mathbf{R}$ & $\mathrm{O}$ & $\mathbf{R}$ & $\mathrm{O}$ & $\mathbf{R}$ & $\mathrm{AD}$ & $\mathrm{UM}$ & B & III & IV & $\mathrm{V}$ & VI & \\
\hline AeovCS-1 & 10 & - & - & - & 1 & - & 4 & - & 4 & - & 402 & 401 & 209 & - & - & - & - & 30 \\
\hline AeovCS-2 & 14 & - & - & - & - & - & 8 & - & 5 & - & 390 & 396 & 210 & - & - & - & - & 30 \\
\hline AeovCS-3 & 16 & - & 2 & - & - & - & 5 & - & 4 & - & 392 & 396 & 208 & - & - & - & - & 30 \\
\hline AeovCS-4 & 18 & - & - & - & - & - & 10 & - & 5 & - & 382 & 392 & 210 & - & - & - & - & 30 \\
\hline AeovCS-5 & 15 & - & 2 & - & - & - & 4 & - & 3 & - & 367 & 371 & 194 & - & - & - & - & 28 \\
\hline Total & 73 & - & 4 & - & 1 & - & 31 & - & 21 & - & 1933 & 1956 & 1031 & - & - & - & - & 148 \\
\hline Aeovph1b-1 & 66 & 9 & 15 & 3 & 13 & - & 25 & 16 & 33 & - & 93 & 153 & 159 & 74 & 13 & 1 & 1 & 30 \\
\hline Aeovph $1 \mathrm{~b}-2$ & 67 & 7 & 7 & 1 & 11 & - & 31 & 12 & 32 & 4 & 110 & 133 & 164 & 61 & 12 & 3 & 3 & 29 \\
\hline Total & 133 & 16 & 22 & 4 & 24 & - & 56 & 28 & 65 & 4 & 203 & 286 & 323 & 135 & 25 & 4 & 4 & 59 \\
\hline
\end{tabular}

$\mathrm{R}=$ ring bivalents; $\mathrm{O}=$ Open bivalents; $\mathrm{III}=$ trivalents; $\mathrm{IV}=$ quadrivalents; $\mathrm{V}=$ pentavalents; $\mathrm{VI}=$ hexavalents. 
This type of configuration can be explained by the existence of translocations involving different genomes in the hybrids. The existence of reciprocal translocations between different homoeologous group has been described in Ae. ovata (Furuta, 1981) in wheat (Sears, 1954; Baker \& McIntosh, 1966; Kobrehel \& Feillet, 1975 ), and it is well known that this cytogenetic mechanism has accompained the evolutionary process of the Triticineae group.

In all cases, the number of bound arms per cell for the different types of homoeologous associations at metaphase I has been calculated as the minimum number of chiasmata that can explain each meiotic configuration. In those configurations where three chromosomes arms were associated at the same point, namely, as in the frying pan and Y-shaped trivalents, the type of association could not be ascertained and, consequently, they were considered undetermined (Un) (Fig. 2d). The number of bound arms for each type of specific association observed in low pairing hybrid plants was the same as the number of meiotic configurations observed, due to the presence of only rod bivalents (Table 1), however in high homoeologous pairing hybrid plants ring bivalents and multivalents were frequent (Table 2). In previous studies of $A e$. ovata $\times T$. aestivum hybrid differences with respect to the number of bound arms per cell have been reported both in the presence and absence of chromosome 5B, this is in agreement with the results obtained in this work (see Table 3). McGuire \& Dvorák (1982) suggested that the variation found among hybrids involving different accessions of Ae. ovata probably reflects genotypic variability for the homoeologous pairing control within this species. The major evidence for the

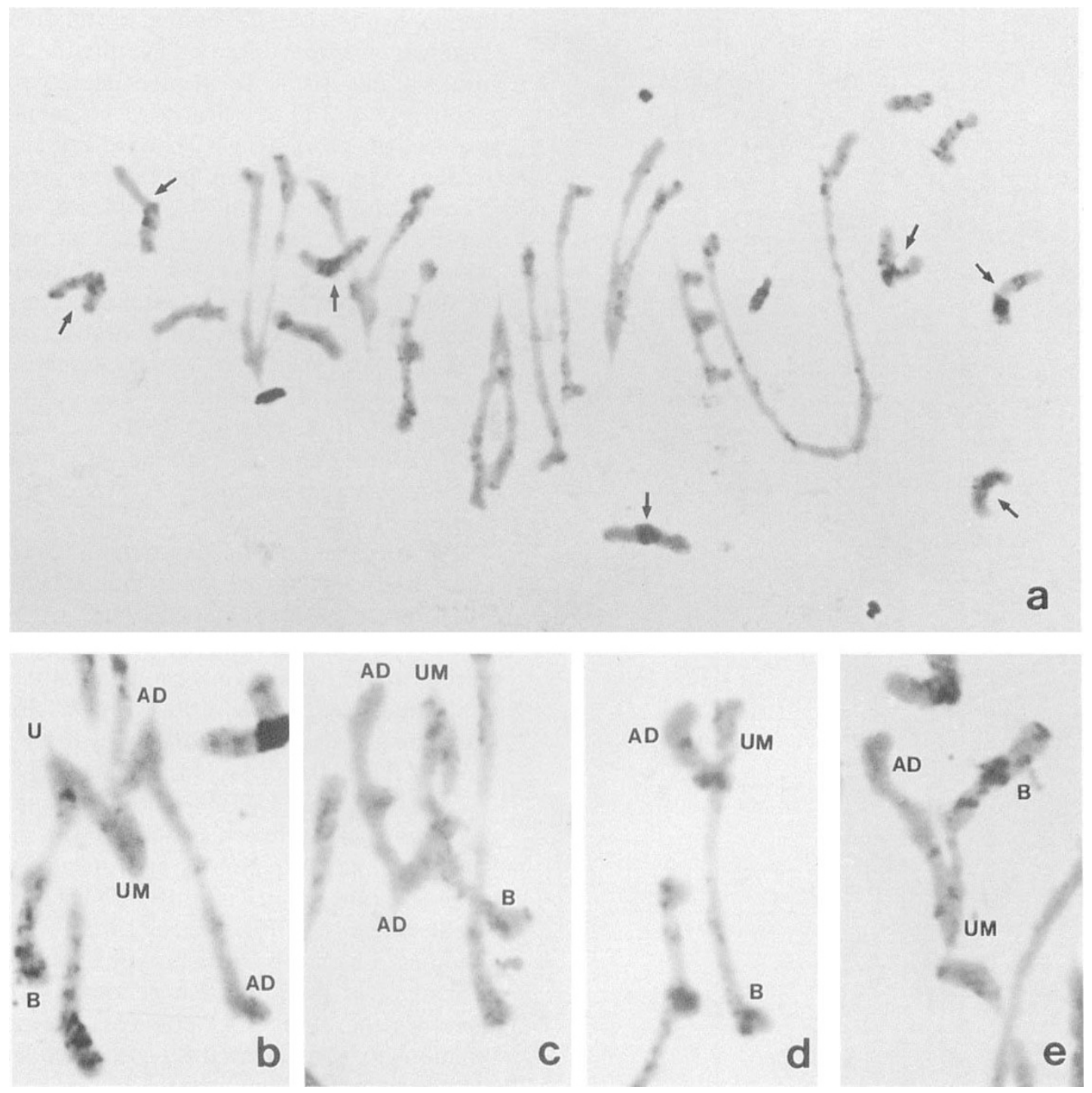

Fig. 2 (a) Metaphase I of Aeovph1b hybrid plant. Arrows indicate chromosomes of B genome. (b) Pentavalent. (c) Quadrivalent. (d) Y-shaped trivalent. (e) V-shaped trivalent. Chromosomes implicated in each configuration are indicated. 
existence of gene(s) that affect(s) homoeologous pairing in Ae. ovata was described by Lacadena \& Azpiazu (1969), who found the highest recorded pairing level (6.68 mean number of bound arms per cell) in hybrids where chromosome 5B was present.

High homoeologous pairing has been analysed by most other authors only when chromosome 5B was absent, and it is well known that there is a promotor gene of homoeologous pairing located in the short arm of chromosome 5B (see Sears, 1976). In our example, as well as in the hybrid analysed by Farroq et al. (1990), this promotor gene is operative but its effect may not be important because our results are similar to those found when this arm is absent in the hybrids (see Table 3).

\section{Genome identification and associations types}

The application of a $\mathrm{C}$-banding technique revealed the existence of three different identifiable chromosome groups at meiosis in Ae. ovata-wheat hybrid plants: (i) genomes $\mathrm{A}$ and $\mathrm{D}$ of wheat were characterized by the absence of prominent C-bands, (ii) B genome of Chinese Spring showed prominent pericentromeric $\mathrm{C}$-bands and (iii) $\mathrm{U}$ and $\mathrm{M}$ genomes of Ae. ovata had dispersed and intercalary $\mathrm{C}$-heterochromatin. In the pentaploid hybrids (genome constitution ABDUM), 10 different types of homoeologous association at metaphase I could occur but only five types were distinguishable, i.e. between $\mathrm{A}$ or $\mathrm{D}$ genomes and $\mathrm{U}$ or $\mathrm{M}$ chromosomes (AD-UM), between A or D chromosomes and $B$ genome $(A D-B)$, between $U$ or $M$ chromosomes and $B$ genome of wheat (UM-B), between $\mathrm{A}$ and $\mathrm{D}$ genomes $(\mathrm{A}-\mathrm{D})$ and between $\mathrm{M}$ and $\mathrm{U}$ chromosomes (U-M).

If pairing takes place at random among the five wheat and Aegilops genomes one would expect the following relative order: $\mathrm{AD}-\mathrm{UM}>\mathrm{AD}-\mathrm{B}=\mathrm{UM}-\mathrm{B}$ $>\mathrm{A}-\mathrm{D}=\mathrm{U}-\mathrm{M}$, in a ratio $4: 2: 2: 1: 1$, that is the meiotic pairing would depend only on the number of genomes implicated in each type of association. However, in all situations the five types of distinguishable associations showed the following relative order; $A D-U M>A-D$ $>\mathrm{U}-\mathrm{M}>\mathrm{AD}-\mathrm{B}>\mathrm{UM}-\mathrm{B}$ in both low and high homoeologous pairing hybrids. This result indicates that wheat (A and D) genomes and Aegilops ( $\mathrm{U}$ and $\mathrm{M}$ ) genomes show greater affinity with each other than do wheat-wheat (AD-B) or Aegilops-wheat (UM-B) genomes. The more frequent type should be AD-UM as it involves four different genomes (AD-UM) and therefore the number of possible chromosome combinations to be associated is higher than with the other types (two or three genomes). 
Table 3 Mean number of bound arms per cell in wheat $-A$ e. ovata hybrids previously reported

\begin{tabular}{|c|c|c|c|c|}
\hline Cross & $\begin{array}{l}\text { Chromosome } \\
\text { number }\end{array}$ & $\begin{array}{l}\text { Chromosome } \\
\text { 5B }\end{array}$ & $\begin{array}{l}\text { Mean chiasmata } \\
\text { per cell }\end{array}$ & Reference \\
\hline $\mathrm{CS} \times$ Ae, ovata & 35 & Present & 0.43 & Abu Baker \& Kimber, 1982 \\
\hline $\begin{array}{l}\text { Ae. ovata } \times \text { T. aestivum } \\
\text { ssp. aestivum }\end{array}$ & 35 & Present & 1.05 & Claesson et al., 1990 \\
\hline $\begin{array}{l}\text { T. aestivum } \mathrm{ssp} \text {. } \\
\text { aestivum } \times \text { Ae. ovata }\end{array}$ & 35 & Present & 0.76 & Claesson et al., 1990 \\
\hline $\mathrm{CS} \times A$, ovata & 35 & Present & 2.32 & McGuire \& Dvorák, 1982 \\
\hline $\begin{array}{c}\text { CS Mono } 5 \mathrm{~B} \times \text { Florence } \\
\text { Aurore } \times \text { Ae. ovata }\end{array}$ & 35 & Present & 6.68 & Lacadena \& Azpiazu, 1969 \\
\hline $\mathrm{CS} \times$ Ae. ovata & 35 & Present & 1.40 & Farroq et al., 1990 \\
\hline Ae. ovata $\times \mathrm{CS}$ & 35 & Present & 0.88 & This work \\
\hline Ae. ovata $\times \mathrm{CS} p h l b$ & 35 & Present & 13.43 & This work \\
\hline $\mathrm{CS} p h l b \times$ Ae. ovata & 35 & Present & 12.50 & Farroq et al., 1990 \\
\hline CS Nulli $5 \mathrm{~B} \times A e$. ovata & 34 & Absent & 12.88 & Abu Bakar \& Kimber, 1982 \\
\hline $\mathrm{CS}$ Nulli $5 \mathrm{~B} \times$ Ae. ovata & 34 & Absent & 13.29 & McGuire \& Dvorák, 1982 \\
\hline $\begin{array}{l}\text { CS Mono } 5 \mathrm{~B} \times \text { Mentanna } \times \\
\text { Ae. ovata }\end{array}$ & 34 & Absent & 13.54 & Lacadena \& Azpiazu, 1969 \\
\hline
\end{tabular}

$\mathrm{CS}=$ Chinese Spring

\section{Genome affinities and genome relationships in wheat and Ae. ovata}

The type of association in which equal numbers of genomes are implicated could supply additional information about the genome affinities expressed, if they exist, because the same mean number of associated arms at metaphase $I$ is expected for all those types if preferential pairing does not occur. The comparisons carried out between $\mathrm{U}-\mathrm{M}$ and $\mathrm{A}-\mathrm{D}$ types, both in low and high pairing hybrids, indicate that the affinities expressed between $\mathrm{U}$ and $\mathrm{M}$ genomes of Ae. ovata are similar to those of $A$ and $D$ genomes of wheat but comparisons involving the high pairing hybrids should be interpreted cautiously as only two plants have been analysed. Likewise, associations between $U$ and $M$ genomes with the $\mathrm{B}$ genome of wheat are similar to the A or D ones with B, because no significant deviation was detected (see Table 4). These results presumably indicate that the $\mathrm{B}$ genome of wheat is no more closely related to the other wheat genomes than to genomes of Ae. ovata. Dvorák \& McGuire (1981) suggested that the differences in the amount of heterochromatin could explain the variation in chromosome pairing among wheat genomes. Ferrer et al. (1984) studied the meiotic pairing of nine wheat chromosomes ( $\mathrm{B}$ genome, 4A and $7 \mathrm{~A}$ ) and concluded that the effect of heterochromatin is clear in the homoeologous chromosomes of groups $4(4 \mathrm{~A}$ and $4 \mathrm{~B})$ and 7 (7A and $7 \mathrm{~B})$. $\mathrm{C}$-heterochromatin content, however, might be responsible for the lower pairing usually observed for the B genome when it is compared with $\mathrm{A}$ or $\mathrm{D}$ genomes, but it is also probable that chromosomes of the B genome exhibit lower pairing as a characteristic in their own right. Unfortunately the variability for C-heterochromatin, which is necessary to distinguish between both mechanisms, has not been described in wheat.

If the mean number of associated arms at metaphase I is taken as a measure of the genome relationships among the different genomes that are present in hybrid combinations, one could expect that the affinities would be maintained in hybrids with different levels of pairing (low and high) as well as in different meiotic configurations (bivalents and multivalents) within the same level of pairing.

The differences between the hybrids analysed (low and high pairing) make it necessary to develop a new

Table 4 Comparisons between the mean number of associations per cell observed for those types of pairing involving the same number of genomes $(\mathrm{AD}-\mathrm{B} / \mathrm{UM}-\mathrm{B}$, $\mathrm{A}-\mathrm{D} / \mathrm{U}-\mathrm{M})$, in both low and high homoeologous pairing crosses. In all cases paired $t$ tests were performed

\begin{tabular}{|c|c|c|c|c|c|c|}
\hline & \multicolumn{6}{|c|}{ Type of association } \\
\hline & $\mathrm{AD}-\mathrm{B}$ & & UM-B & $A-D$ & & $\mathrm{U}-\mathrm{M}$ \\
\hline $\begin{array}{l}\text { AeovCS } \\
t \text {-value } \\
(\text { d.f. }=4)\end{array}$ & 0.03 & 1.081 & 0.01 & 0.21 & 2.310 & 0.14 \\
\hline $\begin{array}{l}\text { Aeovph1b } \\
t \text {-value } \\
\text { (d.f.=1) }\end{array}$ & 1.10 & 1.486 & 0.58 & 3.80 & 7.000 & 1.91 \\
\hline
\end{tabular}


method that takes into account the amount of pairing for the different distinguishable types of associations relative to the total associations. Thus, the mean number of associations per total number of associations represents the 'relative contribution' of each type of pairing. In order to analyse whether different types of meiotic configuration exhibit differences or not in their relative contribution, the mean number of associations per total associations for each type of pairing was compared between bivalents and multivalents in the high pairing hybrid plants. It is apparent from the data in Table 5 that the amount of pairing for the different distinguishable types of associations, relative to the total associations, was maintained in different meiotic configurations, as no significant deviation was detected. This results seems to indicate that in these hybrid combinations the affinities expressed are independent of the type of configurations considered. The comparisons carried out between the relative contributions for the five types of association between hybrids with different level of pairing were only significant for the AD-B type (see Table 6). These results suggest that in this pentaploid hybrid the affinities expressed are well maintained at different levels of pairing; i.e. the increase in pairing due to the $P h$ gene inactivation is distributed equally among different types of association.

\section{Comparisons with other wheat-Aegilos hybrids}

In wheat-Ae. variabilis and wheat-Ae. kotschyi hybrids (genome constitution ABDUS) it has been recently reported that the relative contribution is not maintained in different meiotic configurations (bivalents and multivalents) or in different levels of pairing (Fernández-Calvín \& Orellana, 1991). The results obtained thus support the idea that chiasma frequency plays an important role in the relative contribution of each type of specific association to the total amount of pairing observed at metaphase I, mainly due to the presence of a differential excess of ring bivalents (with at least two chiasmata) in the high pairing hybrids, which provoke deviations in the relative contribution in different meiotic configurations as well as in hybrids with different level of pairing. Obviously, in the Chinese Spring $\times$ Ae. ovata high pairing hybrids there is an increase in ring bivalents. In fact, this tendency can be observed in these hybrids, so, the A-D type exhibits the highest ring bivalent frequencies in the high pairing hybrids in spite of this type not being the most frequently occurring in the low pairing hybrids (Table 1). This increase, however, may not be sufficiently different to allow the detection of deviations in the relative contribution.

If pairing frequencies can be taken as a measure of

Table 5 Comparisons of the relative contribution for all types of distinguishable associations between bivalents (II) and multivalents (Mult) in high-pairing hybrids

\begin{tabular}{|c|c|c|c|c|c|c|c|c|c|c|c|c|c|c|c|}
\hline & \multicolumn{15}{|c|}{ Mean number of associations/total associations } \\
\hline & \multicolumn{3}{|c|}{ AD-UM } & \multicolumn{3}{|c|}{$\mathrm{AD}-\mathrm{B}$} & \multicolumn{3}{|c|}{ UM-B } & \multicolumn{3}{|l|}{$A-D$} & \multicolumn{3}{|l|}{$\mathrm{U}-\mathrm{M}$} \\
\hline & II & & Mult & II & & Mult & II & & Mult & II & & Mult & II & & Mult \\
\hline $\begin{array}{l}\text { Mean } \\
t \text {-value } \\
(\text { d.f. }=1)\end{array}$ & 0.41 & 1.000 & 0.43 & 0.08 & 0.385 & 0.10 & 0.06 & 7.999 & 0.03 & 0.28 & 0.999 & 0.29 & 0.18 & 2.333 & 0.10 \\
\hline
\end{tabular}
Table 6 Comparisons of the relative contribution for all types of distinguishable associations between low- and high-pairing
hybrids

Mean number of associations/total associations

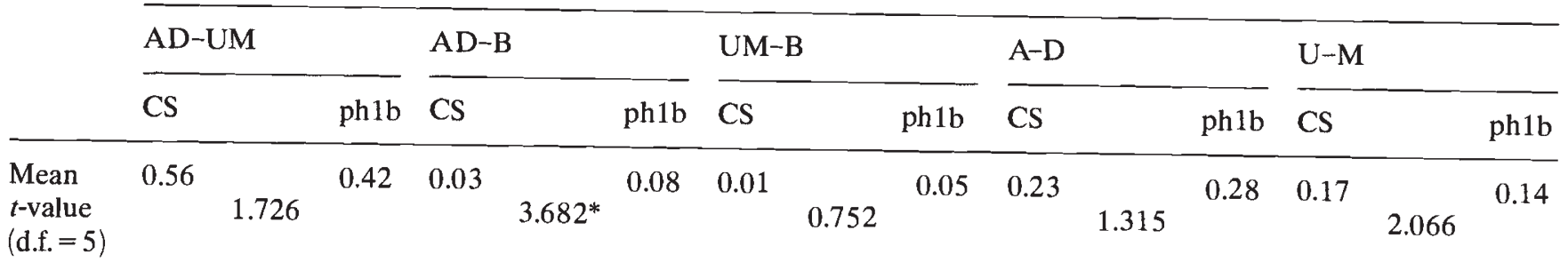

* Significant at the level of 5 per cent. 


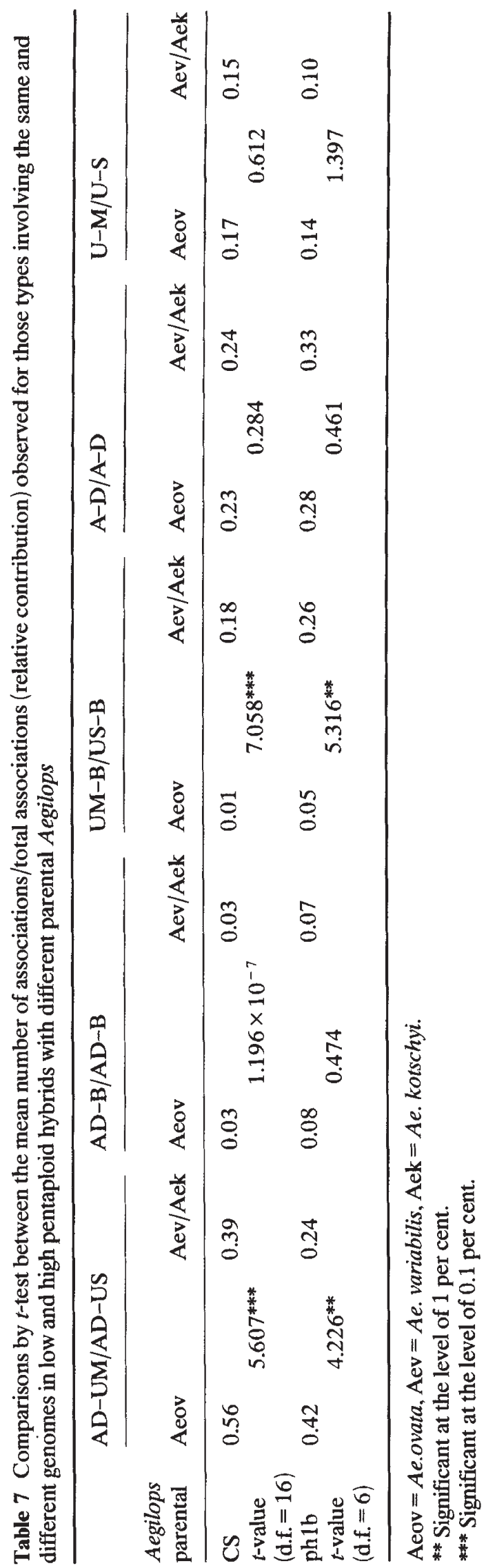

the affinities between the genomes that are in competition, one should expect that these affinities are expressed in the same way in different wheat-Aegilops hybrid combinations for those specific types of association that can be distinguished in all hybrids, i.e. the $\mathrm{A}-\mathrm{D}$ and $\mathrm{AD}-\mathrm{B}$ types should show the same relative contribution in $A e$. ovata-wheat as in Ae.variabiliswheat and $A e$. kotschyi-wheat hybrids at the same level of pairing, unless these genomes $(\mathrm{A}, \mathrm{D}, \mathrm{B})$ exhibit strong interactions with genomes $\mathrm{S}$ of $A e$. variabilis and $A e$. kotschyi or M of Ae. ovata that alter their own affinities. In order to determine whether the expression of affinities between homoeologous chromosomes in hybrid combinations could be altered by the presence of different genomes, the mean number of associations per total associations for those types that involve the same and different genomes was compared between pentaploid hybrids involving different Aegilops species (Ae. ovata and Ae. kotschyi or Ae. variabilis). It is apparent from the data in Table 7 that the pairing affinity between $\mathrm{A}$ and $\mathrm{D}$ genome chromosomes $(\mathrm{A}-\mathrm{D})$ of $T$. aestivum and between $\mathrm{A}$ and $\mathrm{D}$ with $\mathrm{B}$ chromosomes $(\mathrm{AD}-\mathrm{B})$ is the same in hybrid combinations with a different genome constitution. This seems to indicate that the relative contribution within wheat genomes in these hybrid combinations is unaffected by the existence of different Aegilops genomes, although the affinities expressed between wheat and Aegilops genomes are different in both pentaploid hybrids.

The types of pairing involving wheat and Aegilops chromosomes do not contribute in the same way in both types of genome combination (ABDUS, ABDUM), probably due to the existence of different affinities. Therefore, the $\mathrm{U}$ and $\mathrm{S}$ genomes of $A e$. variabilis and $A e$. kotschyi are derived from those of Ae. umbellulata and Ae. sharonensis, respectively (Tanaka, 1955), and it is reasonable to assume that most of US-B associations are actually B-S, due to the close evolutionary proximity between $\mathrm{B}$ and $\mathrm{S}$ genomes (Kushnir \& Halloran, 1981). On the other hand Ae. ovata is an allotetraploid of Ae. umbellulata (U genome) and $A$ e. comosa (M genome) (Kihara, 1954; Kimber \& Abu-Bakar, 1979). There is clearly therefore less affinity between $M$ and $B$ genomes and thus the UM-B associations are lower. It is worth mentioning that $\mathrm{U}-\mathrm{M}$ and $\mathrm{U}-\mathrm{S}$ associations show the same relative contribution in both hybrid combinations. The differences between the more frequent types (AD-UM $>$ AD-US) can presumably be attributed to pairing between D and M genomes (Maan \& Sasakuma, 1978).

The constancy of the relative contribution of those types that only involve wheat genomes might be explained by the existence of a compensating effect with respect to the affinities between wheat and 
Aegilops chromosomes in both genome combinations. The meiotic analysis of new pentaploid wheatAegilops combinations, using differential staining methods, could provide new information about the factors that can affect the expression of the genome affinities and consequently obtain a better understanding of the evolutionary process in the Triticineae.

\section{Acknowledgements}

This work was supported by a grant number AGR880051 from the Comision Interministerial de Ciencia y Tecnologia (CICYT) of Spain.

\section{References}

ABU BAKAR, M. AND KIMBER, G. 1982. Chromosome pairing regulators in the former genus Aegilops. Z.Pflanzen züchtg., 89, 130-138.

BAKER, E. D. AND MCINTOSH, R. A. 1966. Chromosome translocation identified in varieties of common wheat. Can. J. Genet. Cytol, 8, 592-599.

ClAESSON, L., KOTIMAKI, M. AND VON BOTHMER, R. 1990. Crossability and chromosome pairing in some interspecific Triticum hybrids. Hereditas, 112, 49-55.

DVORAK, J. AND MCGUIRE, P. 1981. Nonstructural chromosome differentiation among wheat cultivars, with special reference to differentiation of chromosome in related species. Genetics, 97, 391-414.

FAROOQ, S., IQBAL, N. AND SHAH, T. M. 1990. Intergeneric hybridization for wheat improvement. II. Utilization of the $p h 1 b$ mutant for direct alien introgression into cultivated wheat and production of backcross seed. Cereal Res. Comm., 18 , 21-26.

FERRER, E., GONZALEZ, J. M. AND Jouve, N. 1984. The meiotic pairing of nine wheat chromosomes. Theor. Appl. Genet., 69, 193-198.

FERNANDEZ-CALVIN, B. AND ORELlanA, J. 1991. Metaphase I bound arms frequency and genome analysis in wheat-Aegilops hybrids. 1. Ae variabilis-wheat and Ae. kotschyi-wheat hybrids with low and high homoeologous pairing. Theor. Appl. Genet., (in press).

FURUTA, Y. 1981. Chromosome structural variation in Aegilops ovata. Jpn. J. Genet., 56, 287-294.

GiRALDEZ, R., CERMEÑo, M. C. AND oRellana, J. 1979. Comparison of C-banding pattern in the chromosome of inbred lines and open pollinated varietes of rye. $Z$. Pflanzenzüchtg., 83, 40-48.
KIHARA, H. 1954. Considerations on the evolution and distribution of Aegilops species based on the analyser method. Cytologia, 19, 336-357.

KIMBER, G. 1984. Evolutionary relationships and their influence on plant breeding. In: Gustafson, J. P. (ed.) Gene Manipulation in Plant Improvement, 16th edn., Stadler Genetic Symposium, New York. pp. 281-293.

KIMBER, G. AND ABU-BAKAR, M. 1979. Wheat hybrid information system. Cereal Res. Comm., 7, 257-260.

KOBREHEL, K. AND FEILLET, P. 1975. Identification of genomes and chromosomes involved in peroxidase synthesis of wheat seeds. Can. J. Genet. Cytol., 53, 2334-2335.

KUSHNIR, U. AND Halloran, G. M. 1981. Evidence for Aegilops sharonensis Eig. as the donor of the $\mathrm{B}$ genome of wheat. Genetics, 99, 495-512.

LACADENA, J. R. AND AZPIAZU, A. 1969. Introduction of alien variation into wheat by gene recombination. Il. Action of the $5 \mathrm{~B}$ genetic system on the meiotic behaviour of mono 5B Triticum aestivum L. $\times$ Aegilops ovata L. hybrids. Genet. Ibérica, 21, 1-10.

LILIENFELD, F. A. AND KIHARA, H. 1951. Genome analysis in Triticum and Aegilops, concluding review. Cytologia, 16 , 101-123.

MAAN, S. S. AND SASAKUMA, T. 1978. Chromosome pairing relationships among the D and $\mathrm{M}$ genomes of Triticum and Aegilops species. In: Ramanukam, S. (ed.), Proceedings of the 5th International Wheat Genetics Symposium, New Delhi. pp. 322-331.

MCGUIRE, P. E. AND DVORAK, J. 1982. Genetic regulation of heterogenetic chromosome pairing in polyploid species of the genus Triticum sensu lato. Can. J. Genet. Cytol., 24, 57-82.

PASQUINI, M. 1980. Disease resistance in wheat: II. Behaviour of Aegilops species with respect to Puccinia recondita F. Sp. Tritici, Puccinia graminis F. Sp. Tritici and Erysiphe graminis F. Sp. Tritici. Genet. Agr., 34, 133-148.

RILEY, R., F. R. S., LAW, C. N. AND CHAPMAN, v. 1981. The control of recombination. Phil. R. Soc. Lond., B, 292, 529-534.

SEARS, E. R. 1954. The aneuploids of common wheat. Mo. Agr. Exp. Sta. Res., Bull., 572, 58.

SEARS, E. R. 1976. Genetic control of chromosome pairing in wheat. Ann. Rev. Genet., 10, 31-51.

SEARS, E. R. 1977. An induced mutant with homoeologous pairing in common wheat. Can. J. Genet. Cytol., 19, 585-593.

TANAKA, M. 1955. Chromosome pairing in hybrids between Ae. sharonensis and some species of Aegilops and Triticum. Wheat. Inf. Serv., 2, 7-8.

THOMAS, H. 1981. Interspecific manipulation of chromosomes. Phil. Trans. R. Soc. Lond., B, 292, 519-527. 